\title{
A Heuristic Approach for Solving the Fixed Charge Transportation Problems
}

\author{
KHALID M. ALTASSAN \\ King Saud University, College of Business Administration, Saudi Arabia.
} Email: kaltassan@ksu.edu.sa

\section{MAHMOUD M. EL-SHERBINY}

King Saud University, College of Business Administration, Saudi Arabia Formerly at Institute of Statistical Studies and Research (ISSR), Cairo University, Egypt.

Email: msherbiny@ksu.edu.sa

ALY M. RAGAB

Institute of Statistical Studies and Research (ISSR), Cairo University, Giza, Egypt. Email: alyragab@hotmail.com

BOKKASAM SASIDHAR

King Saud University, College of Business Administration, Saudi Arabia. Email: bbokkasam@ksu.edu.sa

\begin{abstract}
Most of researchers use the relaxed transportation problem proposed by (Balinski, 1961) to find approximate solution for the fixed charge transportation problem (FCTP). This approximated solution is considered as a lower limit for the optimal solution of FCTP. In this paper a heuristic approach has been developed to find an approximate solution used as a lower limit for the FCTP which is better than that is found by (Balinski, 1961). The same has been validated by applying the algorithm on 37 examples and testing for the significance of results. The algorithm is based on applying the Vogel approximation method on the relaxed transportation problem. In addition, an illustrative numerical example is given to show the simplicity of applying the proposed approach.
\end{abstract}

Keywords: Transportation Problem, Fixed Charge, Heuristic Methods.

\section{Introduction}

The fixed-charge problem deals with situations in which the activity incurs two types of costs: a fixed cost that must be incurred to start the activity and a variable cost that is directly proportional to the level of the activity. The fixed-charge transportation problem (FCTP) is a special case of the transportation problem where a fixed charge is associated with each route that can be opened, in addition to the variable transportation cost proportional to the amount of goods shipped. The objective is to select a distribution scheme with the minimum total cost. The FCTP is considered to be an NP-hard problem (Altassan, ElSherbiny, \& Sasidhar, 2013) and was first formulated in (Hirsch \& Dantzig, 1954). In the literature, several algorithms have been proposed for solving this problem but the known exact ones are generally not very useful when a problem reaches a certain dimension. Therefore, some heuristic methods have been 
developed. Some of them are in (Adlakha \& Kowalski, 2003; Adlakha, Kowalski, \& Vemuganti, 2006; Cooper, 1975; Diaby, 1991; Gottlieb \& Paulmann, 1998; Palekar, Karwan, \& Zionts, 1990; Sun, Aronson, McKeown, \& Drinka, 1998) .

An analytical branching method to solve the FCTP starting with a linear formulation of the problem that converges to an optimal solution by sequentially separating the fixed costs and finding a direction to improve the value of the objective function of the linear formulation has been proposed in (Adlakha, Kowalski, \& Lev, 2010). An approximation for the lower bound of the FCTP is presented in (Adlakha, Kowalski, Wang, Lev, \& Shen, 2014) and claimed that it is much superior to the lower bound developed in (Balinski, 1961). However, in the process, it was transformed to an NLP problem, which is computationally not simple.

\section{The Fixed-charge Transportation Problem}

The transportation model is a special case of the linear programming problem. It deals with transporting certain product from $m$ sources to $n$ destinations. The sources are production facilities with respictive capacities $a_{1}, a_{2}, \ldots, a_{m}$ and the destinations are warehouses with required levels of demands $b_{1}, b_{2}, \ldots, b_{n}$. The penality for transporting one unit of the given product from the source $i$ to the destination $j$ is $c_{i j}$. In the (FCTP) an additional fixed cost $f_{i j}$ is assumed for opening the route $(i, j)$ and the problem is to determine the amounts to be transported from all sources to all destinations such that the total transportation cost is minimized while satisfying both the supply limits and the demand requirements.

The mathematical model of the FCTP can be represented as follows:

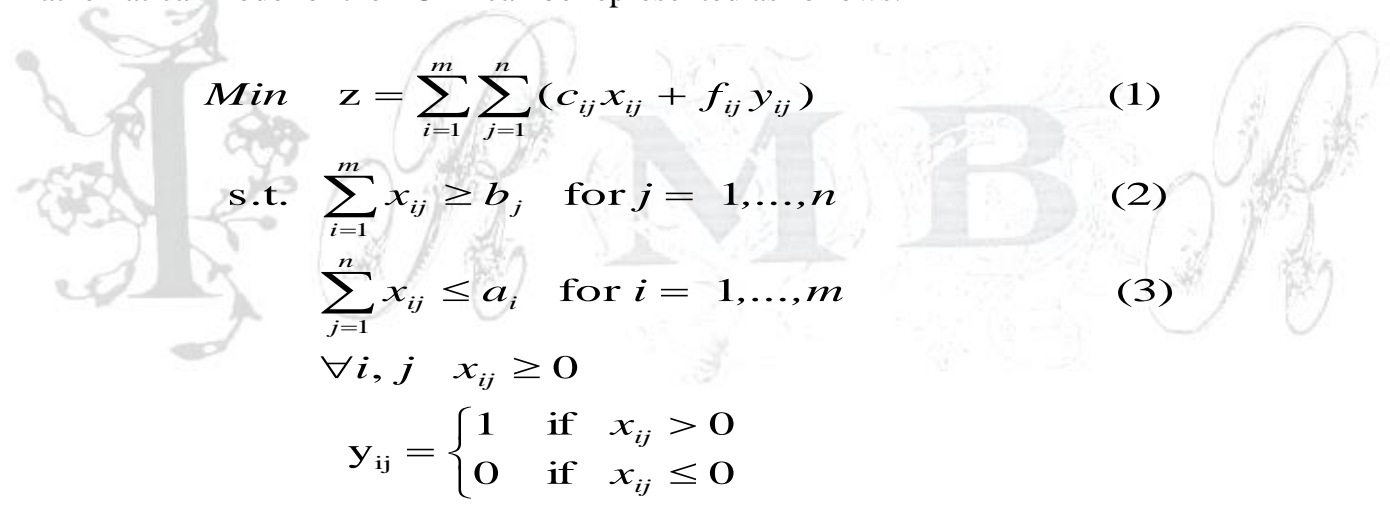

Where $x_{i j}$ is the unknown quantity to be transported through the route $(i, j)$.

\section{The Proposed Algorithm}

This algorithm gives a better approximate solution for the FCTP that given in (Balinski, 1961). The proposed algorithm is an improved version of that Vogel Approximation Method (VAM) that generally produces a approximate solution for the traditional transportation problem. The basic idea of the algorithm is in adjusting the cost matrix of the Relaxed Transportation Problem (RTP), after each allocation (iteration) according to the changes in the supply and demand. The following steps illustrate the proposed algorithm:

Step1: Construct the Balinski RTP by relaxing the integer condition on $y_{i j}\left(y_{i j}=f_{i j} / m_{i j}\right)$ and the unit transportation $\operatorname{cost} C_{i j}$ can be represented by (4).

$$
C_{i j}=c_{i j}+f_{i j} / m_{i j}
$$




$$
\text { Where } m_{i j}=\left\{\begin{array}{cc}
\min \left(a_{i}, b_{j}\right) & \text { if } a_{i}, b_{j}>0 \\
a_{i} & \text { if } b_{j}=0 \\
b_{j} & \text { if } a_{i}=0
\end{array}\right.
$$

Step 2: For each row (column), determine a penalty by subtracting the smallest unit cost element in that row (column) from the next smallest unit cost element in the same row (column).

Step 3: Identify the row or column with the largest penalty. Break ties arbitrarily. Allocate as much as possible to the cell with the least cost in the identified row or column. Adjust the supply and demand, and cross out the satisfied row or column. If a row and a column are satisfied simultaneously, only one of the two is crossed out.

Step 4: If exactly one row (column) with positive supply (demand) remains uncrossed out, allocate this supply (demand) in the remaining uncrossed out cells with their unsatisfied demands (supply) of the uncrossed out column (row) and Stop. Otherwise go to step 5.

Step 5: Adjust the last cost matrix by recalculating the $C_{i j}$ for the uncrossed out row (column) identified in step 3. Go to step 3 .

\section{Numerical Example}

Consider a company with four factories in locations $S_{1}, S_{2}, S_{3}$ and $S_{4}$ which produce a specific type of product. There are six other locations $D_{1}, D_{2}, D_{3}, D_{4}, D_{5}$ and $D_{6}$ that receive this product as consumers. The supply $S_{i}$, the demand $D_{j}$, the cost $f_{i j}$ for opening the route $(i, j)$ and the unit cost $c_{i j}$ for transporting one unit of the given product from the source $i$ to the destination $j$ are given in Table 1 .

\begin{tabular}{|cccccccc|}
\multicolumn{7}{c|}{ Table1: Cost matrix $f_{i j}, c_{i j}[13]$} \\
\hline & $D_{1}$ & $D_{2}$ & $D_{3}$ & $D_{4}$ & $D_{5}$ & $D_{6}$ & Supply \\
\hline$S_{1}$ & $11,0.69$ & $16,0.64$ & $18,0.71$ & $17,0.79$ & $10,1.7$ & $20,2.83$ & 45 \\
$S_{2}$ & $14,1.01$ & $17,0.75$ & $17,0.88$ & $13,0.59$ & $15,1.5$ & $13,2.63$ & 35 \\
$S_{3}$ & $12,1.05$ & $13,1.06$ & $20,1.08$ & $17,0.64$ & $13,1.22$ & $15,2.37$ & 20 \\
$S_{4}$ & $16,1.94$ & $19,1.5$ & $15,1.56$ & $11,1.22$ & $15,1.98$ & $12,1.98$ & 15 \\
\hline Demand & 35 & 30 & 25 & 15 & 5 & 5 & \\
\hline
\end{tabular}

Step 1: The Balinski RTP can be represented as in Table 2.

Table2: Balinski's RTP matrix with $C_{i j}=c_{i j}+f_{i j} / m_{i j}$

\begin{tabular}{|cccccccc|}
\hline & $D_{1}$ & $D_{2}$ & $D_{3}$ & $D_{4}$ & $D_{5}$ & $D_{6}$ & Supply \\
\hline$S_{1}$ & 1.00 & 1.17 & 1.43 & 1.92 & 3.70 & 6.83 & 45 \\
$S_{2}$ & 1.41 & 1.32 & 1.56 & 1.46 & 4.50 & 5.23 & 35 \\
$S_{3}$ & 1.65 & 1.71 & 2.08 & 1.77 & 3.82 & 5.37 & 20 \\
$S_{4}$ & 3.01 & 2.77 & 2.56 & 1.95 & 4.98 & 4.38 & 15 \\
\hline Demand & 35 & 30 & 25 & 15 & 5 & 5 & \\
\hline
\end{tabular}

Step 2: Calculation of the penalty of each row $\left(P_{i}\right)$ and of each column $\left(P_{j}\right)$ is shown in Table 3.

Table 3: $\left(P_{i}\right)$ and $\left(P_{j}\right)$

\begin{tabular}{|ccccccccc|}
\hline & $D_{1}$ & $D_{2}$ & $D_{3}$ & $D_{4}$ & $D_{5}$ & $D_{6}$ & Supply & $P_{i}$ \\
\hline$S_{1}$ & 1.00 & 1.17 & 1.43 & 1.92 & 3.70 & 6.83 & 45 & 0.17 \\
$S_{2}$ & 1.41 & 1.32 & 1.56 & 1.46 & 4.50 & 5.23 & 35 & 0.09 \\
$S_{3}$ & 1.65 & 1.71 & 2.08 & 1.77 & 3.82 & 5.37 & 20 & 0.06 \\
$S_{4}$ & 3.01 & 2.77 & 2.56 & 1.95 & 4.98 & $\mathbf{4 . 3 8}$ & 15 & 0.61 \\
\hline Demand & 35 & 30 & 25 & 15 & 5 & 5 & & \\
\hline$P_{j}$ & 0.41 & 0.14 & 0.13 & 0.32 & 0.12 & $\mathbf{0 . 8 5}$ & & \\
\hline
\end{tabular}


Step 3: From Table 3, the sixth column has the maximum penalty $(0.85)$ and the minimum cost in this column is 4.38 in the cell $(4,6)$. So, the cell $(4,6)$ is allocated with the maximum possible value $(5$ units) which is the minimum of $S_{4}$ and $D_{6}$. Cross out the column $D_{6}$ corresponding to this minimum. The uncrossed out row is the fourth row, then change the supply $S_{4}$ to 10 . The result of this step is allocating 5 units in the cell $(4,6)$. This means that $x_{46}=5$.

Step 4: Since there are more than one row (column) with positive supply (demand) uncrossed out, go to step 5 .

Step 5: Since the uncrossed out row in step 3 is $S_{4}$, calculate the costs $C_{4 j}$ for row $S_{4}$ based on its new supply (10). The new cost matrix is presented in Table 4 . Note that the costs in row $S_{4}$ only are changed due to changing $S_{4}$ from 15 to 10 . Go to step 3 .

Table 4: Cost Matrix from Step 4

\begin{tabular}{|cccccccc|}
\hline & $D_{1}$ & $D_{2}$ & $D_{3}$ & $D_{4}$ & $D_{5}$ & Supply & $P_{i}$ \\
\hline$S_{1}$ & 1.00 & 1.17 & 1.43 & 1.92 & 3.70 & 45 & 0.17 \\
$S_{2}$ & 1.41 & 1.32 & 1.56 & 1.46 & 4.50 & 35 & 0.09 \\
$S_{3}$ & 1.65 & 1.71 & 2.08 & 1.77 & 3.82 & 20 & 0.06 \\
$S_{4}$ & 3.54 & 3.40 & 3.06 & $\mathbf{2 . 3 2}$ & 4.98 & 10 & $\mathbf{0 . 7 4}$ \\
\hline Demand & 35 & 30 & 25 & 15 & 5 & & \\
\hline$P_{j}$ & 0.41 & 0.14 & 0.13 & 0.32 & 0.12 & & \\
\hline
\end{tabular}

Step 3: From Table 4, the row $S_{4}$ has the maximum penalty $(0.74)$ and the minimum cost in this row is 2.32 in the cell $(4,4)$, so allocate this cell with 10 units which is the minimum of $D_{4}$ and $S_{4}$.Cross out the row $S_{4}$ corresponding to this minimum. The uncrossed out row is the fourth column. Change the demand $D_{4}$ to 5 . The result of this step is allocating 10 units in the cell $(4,4)$. This means that $x_{44}=$ 10 .

Step 4: Since there are more than one row (column) with positive supply (demand) uncrossed out, go to step 5 .

Step 5: Since the uncrossed out column is $D_{4}$, calculate the costs $C_{i 4}$ for that column based on its new demand (5). The new cost matrix is presented in Table 5.

Table 5: Cost Matrix from Step 5

\begin{tabular}{|cccccccc|}
\hline & $D_{1}$ & $D_{2}$ & $D_{3}$ & $D_{4}$ & $D_{5}$ & Supply & $P_{i}$ \\
\hline$S_{I}$ & 1.00 & 1.17 & 1.43 & 4.19 & 3.70 & 45 & 0.17 \\
$S_{2}$ & 1.41 & 1.32 & 1.56 & 3.19 & 4.50 & 35 & 0.09 \\
$S_{3}$ & 1.65 & 1.71 & 2.08 & 4.04 & 3.82 & 20 & 0.06 \\
\hline Demand & 35 & 30 & 25 & 5 & 5 & & \\
\hline$P_{j}$ & 0.41 & 0.14 & 0.13 & $\mathbf{0 . 8 5}$ & 0.12 & & \\
\hline
\end{tabular}

Step 3: The result of this step is transporting 5 units through the route $(2,4)$. That means $x_{24}=5$.

Step 4: Since there are more than one row (column) with positive supply (demand) uncrossed out, go to step 5.

Step 5: Since the uncrossed out row is $S_{2}$, recalculate the cost $C_{2 j}$. The result of this step is presented in Table 6.

Table 6: Recalculated costs of Step 5

\begin{tabular}{|ccccccc|}
\hline & $D_{1}$ & $D_{2}$ & $D_{3}$ & $D_{5}$ & Supply & $P_{i}$ \\
\hline$S_{1}$ & $\mathbf{1 . 0 0}$ & 1.17 & 1.43 & 3.7 & 45 & 0.17 \\
$S_{2}$ & 1.48 & 1.32 & 1.56 & 4.5 & 30 & 0.09 \\
$S_{3}$ & 1.65 & 1.71 & 2.08 & 3.82 & 20 & 0.06 \\
\hline Demand & 35 & 30 & 25 & 5 & & \\
\hline$P_{j}$ & $\mathbf{0 . 4 7}$ & 0.14 & 0.13 & 0.12 & & \\
\hline
\end{tabular}


Step 3: The result of this step is transporting 35 units through the route $(1,1)$. That means $x_{11}=35$, the $S_{1}$ would be equal to 10 and the crossed out column $D_{l}$.

Step 4: Since there are more than one row (column) with positive supply (demand) uncrossed out, go to step 5.

Step 5: Since the uncrossed out row is $S_{l}$, recalculate the cost $C_{l j}$ as presented in Table 7.

Table 7: Recalculated costs of Step 5

\begin{tabular}{|cccccc|}
\hline & $D_{2}$ & $D_{3}$ & $D_{5}$ & Supply & $P_{i}$ \\
\hline$S_{1}$ & 2.24 & 2.51 & 3.7 & 10 & 0.27 \\
$S_{2}$ & 1.32 & 1.56 & 4.5 & 30 & 0.24 \\
$S_{3}$ & 1.71 & 2.08 & 3.82 & 20 & 0.37 \\
\hline Demand & 30 & 25 & 5 & & \\
\hline$P_{j}$ & 0.39 & $\mathbf{0 . 5 2}$ & 0.12 & & \\
\hline
\end{tabular}

Step 3: The result of this step is transporting 25 units through the route $(2,3)$. That means $x_{23}=25$, the $S_{2}$ would be equal to 5 .

Step 4: Since there are more than one row (column) with positive supply (demand) uncrossed out, go to step 5.

Step 5: Since the uncrossed out row is $S_{2}$, recalculate the costs $C_{2 j}$ of row 2 as presented in Table 8 .

Table 8: Recalculated costs of Step 5

\begin{tabular}{|ccccc|}
\hline & $D_{2}$ & $D_{5}$ & Supply & $P_{i}$ \\
\hline$S_{1}$ & 2.24 & 3.7 & 10 & 1.46 \\
$S_{2}$ & 4.15 & 4.5 & 5 & 0.35 \\
$S_{3}$ & $\mathbf{1 . 7 1}$ & 3.82 & 20 & $\mathbf{2 . 1 1}$ \\
\hline Demand & 30 & 5 & & \\
\hline$P_{j}$ & 0.53 & 0.12 & & \\
\hline
\end{tabular}

Step 3: The result of this step is transporting 20 units through the route $(3,2)$. That means $x_{32}=20$, and $D_{2}$ will be adjusted to 10 .

Step 4: Since there are more than one row (column) with positive supply (demand) uncrossed out, go to step 5.

Step 5: Since the uncrossed out column is $D_{2}$, recalculate the costs $C_{i 2}$ of column 2 as presented in Table 9 .

Table 9: Recalculated costs of Step 5

\begin{tabular}{|ccccc|}
\hline & $D_{2}$ & $D_{5}$ & Supply & $P_{i}$ \\
\hline$S_{1}$ & 2.24 & 3.7 & 10 & 1.46 \\
$S_{2}$ & 4.15 & 4.5 & 5 & 0.35 \\
& & & & \\
\hline Demand & 10 & 5 & & \\
\hline$P_{j}$ & $\mathbf{1 . 9 1}$ & 0.80 & & \\
\hline
\end{tabular}

Step 3: The result of this step is transporting 10 units through the route $(1,2)$. Cross out $D_{2}$ and adjust $S_{1}$ to 0 as in Table 10.

Table 10: Recalculated costs of Step 5

\begin{tabular}{|c|c|c|c|c|}
\hline & $D_{2}$ & $D_{5}$ & Supply & $P_{i}$ \\
\hline$S_{1}$ & & 3.7 & 0 & 1.46 \\
\hline$S_{2}$ & & 4.5 & 5 & 0.35 \\
\hline Demand & & 5 & & \\
\hline$P_{j}$ & & 0.80 & & \\
\hline
\end{tabular}


Step 4: Since there is only one column $\left(D_{5}\right)$ with positive demand (5) uncrossed out, allocate 5 units to the cell $(2,5)$ and stop. The final allocation is shown in Table 11.

Table 11: Final allocation

\begin{tabular}{|cccccccc|}
\hline & $D_{1}$ & $D_{2}$ & $D_{3}$ & $D_{4}$ & $D_{5}$ & $D_{6}$ & Supply \\
\hline$S_{1}$ & 35 & 10 & & & 0 & & 45 \\
$S_{2}$ & & & 25 & 5 & 5 & & 35 \\
$S_{3}$ & & 20 & & & & & 20 \\
$S_{4}$ & & & & 10 & & 5 & 15 \\
\hline Demand & 35 & 30 & 25 & 15 & 5 & 5 & \\
\hline
\end{tabular}

The total variable cost $\sum_{i=1}^{m} \sum_{j=1}^{n} c_{i j} x_{i j}$ of final allocation is 106.3, the total fixed cost $\sum_{i=1}^{m} \sum_{j=1}^{n} f_{i j} y_{i j}$ is 108 and the total cost $\sum_{i=1}^{m} \sum_{j=1}^{n}\left(c_{i j} x_{i j}+f_{i j} y_{i j}\right)$ is 214.3. While the proposed algorithm finds an initial feasible solution with total cost equals 214.3, which is less than the initial feasible solution (the optimal RTP solution) given in (Balinski, 1961) gives total cost of 229.1.

\section{Computational Results and Analysis}

As many as 37 FCTP problems have been chosen, with different dimensions (ranging from $3 \times 4$ up to 17×17) from different references, including from OR library ("OR Library: Testcases for Transportation Problems, Fixed Charge Transportation Benchmark Problems,,") and (Adlakha et al., 2014). Table 12 shows a comparison between the objective functions of the approximate solutions using the proposed algorithm (OFPA) and the results of the approach (OFB) proposed in (Balinski, 1961), who adopted results from (Adlakha et al., 2010). The two approaches gave the same solutions for 7 problems viz., 8, 25, 26, 28, 29, 31 and 32. The approach gave better solutions for 4 problems viz., 9, 17, 35 and 36. In order to establish how close is the objective function of the approximate solution to the optimal solution of the FCTP (OFFCTP), using both the proposed algorithm and the approach in (Balinski, 1961), paired-sample t-test was carried out. The test was carried out on the results of 37 problems considered in Table 12. The results of the test are presented in Tables 13 and 14. It can be observed that the difference between the value of the objective function of the approximate solution by the proposed algorithm and the optimal solution of the FCTP is significantly lower than the difference between the proposed and value of the objective function of the approximate solution by the Balinski's approach (Balinski, 1961) and the optimal solution of the FCTP. Hence the proposed algorithm can be considered superior to that of Balinski's and provides a technique for finding the initial solution for the FCTP.

Table 12: Comparison between the objective functions of approximate solutions using the proposed algorithm and the Balinski's approach.

\begin{tabular}{|c|c|c|c|c|c|c|c|c|c|}
\hline $\begin{array}{l}\mathrm{N} \\
\text { o. }\end{array}$ & $\begin{array}{l}\text { Problem and } \\
\text { Dimension }\end{array}$ & OFPA & OFB & OFFCTP & No. & $\begin{array}{l}\text { Problem and } \\
\text { Dimension }\end{array}$ & OFPA & OFB & OFFCTP \\
\hline 1 & $\operatorname{gr} 4 \times 6$ & 214.3 & 229.1 & 202.35 & 20 & $\operatorname{Ex}(5) 9 \times 9(5)$ & 2666 & 2680 & 2042.50 \\
\hline 2 & $\operatorname{ran} 10 \times 10 \mathrm{a}$ & 1808 & 1736 & 1499 & 21 & $\mathrm{EX}(3) 8 \times 8(3)$ & 2880 & 3001 & 2110.10 \\
\hline 3 & $\operatorname{ran} 10 \times 10 \mathrm{c}$ & 14480 & 16490 & 13007 & 22 & $\mathrm{EX}(2) 8 \times 8(2)$ & 3741 & 4296 & 2854.90 \\
\hline 4 & $\operatorname{ran} 10 \times 12$ & 3365 & 3260 & 2714 & 23 & $\mathrm{EX}(5) 8 \times 8(5)$ & 4139 & 4470 & 3297.20 \\
\hline 5 & $\operatorname{ran} 12 \times 12$ & 2508 & 2683 & 2291 & 24 & $3 \times 4$ & 560 & 570 & 495 \\
\hline 6 & $\operatorname{ran} 13 \times 13$ & 3390 & 3521 & 3252 & 25 & $4 \times 5 a$ & 2590 & 2590 & 2305.40 \\
\hline 7 & $\operatorname{ran} 16 \times 16$ & 4273 & 4333 & 3823 & 26 & $4 \times 5 b$ & 3370 & 3570 & 2633.30 \\
\hline 8 & bk $4 \times 3$ & 360 & 360 & 350 & 27 & $4 \times 5 c$ & 680 & 780 & 653.30 \\
\hline
\end{tabular}




\begin{tabular}{|c|c|c|c|c|c|c|c|c|c|}
\hline 9 & $\operatorname{ran} 17 \times 17$ & 1525 & 1464 & 1373 & 28 & $4 \times 5 d$ & 9900 & 9900 & |8946.70 \\
\hline 10 & bal $8 \times 12$ & 501 & 504.2 & 471.5 & 29 & $4 \times 5 \mathrm{e}$ & 1960 & 1960 & 1743.30 \\
\hline 11 & kow $4 \times 5$ & 265 & 285 & 250 & 30 & $4 \times 5 f$ & 315 & 320 & 305.80 \\
\hline 12 & Kawl4×5 & 335 & 345 & 335 & 31 & $4 \times 5 h$ & 325 & 325 & 296.70 \\
\hline 13 & ran10×10bT & 3491 & 3546 & 2672.80 & 32 & $4 \times 5 i$ & 345 & 345 & 311.70 \\
\hline 14 & ran10×10cT & 16591 & 16653 & 12544.7 & 33 & $3 \times 4$ & 30350 & 30455 & 29950 \\
\hline 15 & $\operatorname{ran} 10 \times 12 \mathrm{~T}$ & 2874 & 3289 & 2326.70 & 34 & $4 \times 5$ & 395 & 405 & 325.70 \\
\hline 16 & $\operatorname{ran} 12 \times 12 \mathrm{~T}$ & 2559 & 2691 & 1972.30 & 35 & $4 \times 6$ & 835 & 805 & 740 \\
\hline 17 & $\operatorname{Ex}(3) 7 x 8$ & 2545 & 2449 & 1970.60 & 36 & $4 \times 5$ & 3170 & 3150 & 2620.00 \\
\hline 18 & $\operatorname{Ex}(15) 7 \times 8(3)$ & 2493 & 2510 & 1974.20 & 37 & $4 \times 5$ & 1350 & 1360 & 1350.00 \\
\hline 19 & $\operatorname{Ex}(6) 7 \times 9(1)$ & 2248 & 2408 & 1894.40 & & & & & \\
\hline
\end{tabular}

Table 13: Paired Samples Statistics

\begin{tabular}{|cc|c|c|c|c|}
\hline & Mean & N & Std. Deviation & Std. Error Mean \\
\hline Pair & $\begin{array}{c}\text { Difference from OFFCTP } \\
\text { to Proposed Algorithm } \\
\text { Difference from OFFCTP } \\
\text { to Balinski Results }\end{array}$ & 472.7338 & 37 & 700.42292 & 115.14882 \\
\hline
\end{tabular}

Table 14: Paired Samples Test Results

\begin{tabular}{|c|c|c|c|}
\hline & & & $\begin{array}{l}\text { Difference from } \\
\text { OFFCTP to Proposed } \\
\text { and that of Balinski }\end{array}$ \\
\hline $\begin{array}{l}\text { Paired Differences } \\
\text { T } \\
\text { Df } \\
\text { Sig. (2-tailed) }\end{array}$ & $\begin{array}{l}\text { Mean } \\
\text { Std. Deviation } \\
\text { Std. Error Mean } \\
\text { 95\% Confidence Interval of } \\
\text { the Difference }\end{array}$ & $\begin{array}{l} \\
\text { Lower } \\
\text { Upper }\end{array}$ & $\begin{array}{c}-117.35135 \\
346.78290 \\
57.01076 \\
-232.97453 \\
-1.72818 \\
-2.058 \\
36 \\
.047\end{array}$ \\
\hline
\end{tabular}

Table 15: Comparison between proposed and Balinski's approaches.

\begin{tabular}{|c|c|c|c|c|c|}
\hline $\begin{array}{c}\text { Problem } \\
\text { No. } \\
\end{array}$ & $\begin{array}{c}\text { Problem and } \\
\text { Dimension }\end{array}$ & $\begin{array}{l}\text { RTP of } \\
\text { OFOB }\end{array}$ & $\begin{array}{l}\text { RTP of } \\
\text { OFOP }\end{array}$ & $\begin{array}{c}\text { Optimal Solution } \\
\text { of the FCTP }\end{array}$ & Reference \\
\hline 1 & gr $4 \times 6$ & 185 & 191.3 & 202.35 & OR Library \\
\hline 2 & $\operatorname{ran} 10 \times 10 \mathrm{a}$ & 1252.4 & 1385.4 & 1499 & OR Library \\
\hline 3 & $\operatorname{ran} 10 \times 10 \mathrm{~b}$ & 2613.5 & 2715.1 & 3073 & OR Library \\
\hline 4 & $\operatorname{ran} 10 \times 10 \mathrm{c}$ & 11203.1 & 12620.7 & 13007 & OR Library \\
\hline 5 & $\operatorname{ran} 10 \times 12$ & 2426.2 & 2526.3 & 2714 & OR Library \\
\hline 6 & $\operatorname{ran} 12 \times 12$ & 1826.5 & 1941.9 & 2291 & OR Library \\
\hline 7 & $\operatorname{ran} 13 \times 13$ & 2691.4 & 2736.1 & 3252 & OR Library \\
\hline 8 & $\operatorname{ran} 16 \times 16$ & 3116.4 & 3314.9 & 3823 & OR Library \\
\hline 9 & bk4×3 & 321.67 & 326.7 & 350 & OR Library \\
\hline 10 & $\operatorname{ran} 17 \times 17$ & 1215.2 & 1374.5 & 1373 & OR Library \\
\hline 11 & bal $8 \times 12$ & 451.2 & 473.6 & 471.5 & OR Library \\
\hline 12 & $\operatorname{ran} 14 \times 18$ & 3016.9 & 3227.5 & 3712 & OR Library \\
\hline 13 & kow $4 \times 5$ & 226 & 258.3 & 250 & Adalkha \\
\hline 14 & Kawl4×5 & 305 & 335.0 & 335 & Adalkha \\
\hline
\end{tabular}


Table 15 shows that the values of the RTP obtained by the proposed approach (OFOP) lies between the values of the RTP given by Balinski's approach (OFOB)(Balinski, 1961) and the optimal solution of the RTP matrix, for some of the problems considered in OR library ("OR Library: Testcases for Transportation Problems, Fixed Charge Transportation Benchmark Problems,,") and (Adlakha et al., 2014). Also, all the values do not penetrate the optimal values of such problems. Hence, the RTP values given by the proposed algorithm can be considered as a lower bound - as a reference - for the optimal solution of FCTP instead of using the RTP value given by the optimal solution of RTP matrix as mentioned in (Adlakha et al., 2010).

\section{Conclusion}

This paper presented a heuristic approach for finding an approximate solution used as a lower bound for the optimal solution of FCTP. This heuristic approach has been applied to a set of problems and the results indicate that it is significantly better. The RTP value using this algorithm can be considered as a better lower bound to the optimal solution of FCTP compared to the RTP value obtained by Baliniski's approach (Balinski, 1961). In addition, the proposed algorithm is simple and computationally feasible as compared to the algorithm presented in (Adlakha et al., 2014) which is dealing with a non-linear formulation of the problem.

\section{Acknowledgement}

This paper is supported by the Research Center at the College of Business Administration and the Deanship of Scientific Research at King Saud University, Riyadh.

\section{References}

Adlakha, V., \& Kowalski, K. (2003). A simple heuristic for solving small fixed-charge transportation problems. Omega, 31(3), 205-211.

Adlakha, V., Kowalski, K., \& Lev, B. (2010). A branching method for the fixed charge transportation problem. Omega, 38(5), 393-397.

Adlakha, V., Kowalski, K., \& Vemuganti, R. (2006). Heuristic algorithms for the fixed-charge transportation problem. Opsearch, 43(2), 132-151.

Adlakha, V., Kowalski, K., Wang, S., Lev, B., \& Shen, W. (2014). On approximation of the fixed charge transportation problem. Omega, 43, 64-70.

Altassan, K. M., El-Sherbiny, M. M., \& Sasidhar, B. (2013). Near Optimal Solution for the Step Fixed Charge Transportation Problem. Applied Mathematics \& Information Sciences, 7(2), 661-669.

Balinski, M. (1961). Fixed cost transportation problems. Naval Research Logistics Quarterly, 8, 41-54.

Cooper, L. (1975). The fixed charge problem-I: a new heuristic method. Computers \& Mathematics with Applications, 1(1), 89-95.

Diaby, M. (1991). Successive linear approximation procedure for generalized fixed-charge transportation problems. Journal of the Operational Research Society, 42(11), 991-1001.

Gottlieb, J., \& Paulmann, L. (1998). Genetic algorithms for the fixed charge transportation problem. Paper presented at the Evolutionary Computation Proceedings, 1998. IEEE World Congress on Computational Intelligence., The 1998 IEEE International Conference on.

Hirsch, W. M., \& Dantzig, G. B. (1954). Notes on Linear Programming, Part XIX: The Fixed Charge Problem: Rand Corporation.

OR Library: Testcases for Transportation Problems, Fixed Charge Transportation Benchmark Problems,.

Palekar, U. S., Karwan, M. H., \& Zionts, S. (1990). A branch-and-bound method for the fixed charge transportation problem. Management Science, 36(9), 1092-1105.

Sun, M., Aronson, J. E., McKeown, P. G., \& Drinka, D. (1998). A tabu search heuristic procedure for the fixed charge transportation problem. European Journal of Operational Research, 106(2-3), 441-456. 